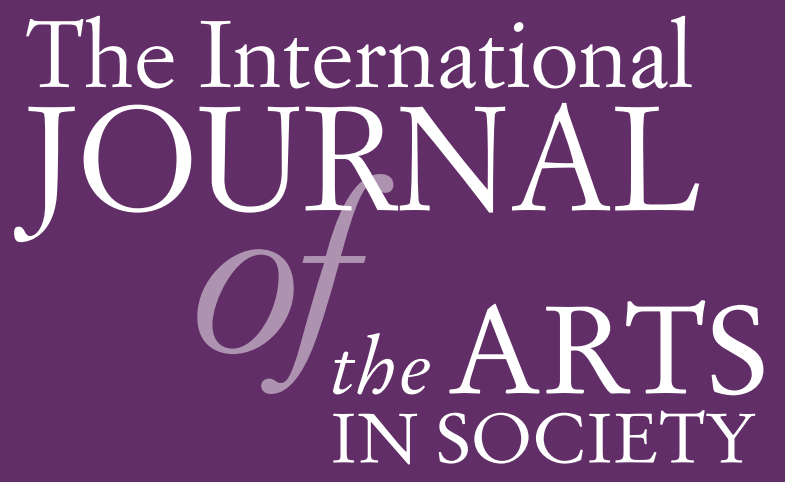

Volume 2, Number 1

The Solar Familiar: Fact and Fiction in Photography and Visual Anthropology

Marcus G. J. Williams and Susan E Jowsey 
THE INTERNATIONAL JOURNAL OF THE ARTS IN SOCIETY http://www.arts-journal.com

First published in 2007 in Melbourne, Australia by Common Ground Publishing Pty Ltd www.CommonGroundPublishing.com.

(C) 2007 (individual papers), the author(s)

(C) 2007 (selection and editorial matter) Common Ground

Authors are responsible for the accuracy of citations, quotations, diagrams, tables and maps.

All rights reserved. Apart from fair use for the purposes of study, research, criticism or review as permitted under the Copyright Act (Australia), no part of this work may be reproduced without written permission from the publisher. For permissions and other inquiries, please contact <cg-support@commongroundpublishing.com>.

ISSN: 1833-1866

Publisher Site: http://www.Arts-Journal.com

THE INTERNATIONAL JOURNAL OF THE ARTS IN SOCIETY is a peer refereed journal. Full papers submitted for publication are refereed by Associate Editors through anonymous referee processes.

Typeset in Common Ground Markup Language using CGCreator multichannel typesetting system http://www.CommonGroundSoftware.com. 


\title{
The Solar Familiar: Fact and Fiction in Photography and Visual Anthropology
}

\author{
Marcus G. J. Williams, Unitec New Zealand, New Zealand \\ Susan E Jowsey, Independent Artist, New Zealand
}

\begin{abstract}
Solar Familiar' takes the form of a 'documentary' project, which investigates the psychological, and physical difficulties of a family displaced from Earth who find themselves inhabitants in the unfamiliar; a family on the extremes of an increasingly displaced population; both historically and culturally. This is a family alienated from the memorized ... rootless, they flounder to resurrect cultural experience, however, without cultural boundaries to define their world the gulf that separates them from their own personal histories and their shared history, has created in them an incomprehension they struggle relentlessly to overcome as if one sense has failed and the other four cannot attune to the loss. The artistic process is collaborative; parents and children from an actual family produce documentation and recreation of an imagined experience, constituting an ethnographic inventory, which in turn forms the basis of a documentary film. The interweaving of the documentary idiom, associated with objectivity and veracity, with fantasy and the conceived space of art raises questions about the mediated nature of the cultural construct; family.
\end{abstract}

Keywords: Cross Disciplinary Art, Family, Collaboration, Visual Anthropology, Saged Photography

C SOLAR FAMILIAR' IS an art project, which through the idiomatic structures of documentary catalogues the psychological, and physical struggles of a family displaced; a family who find themselves inhabitants of the unfamiliar.

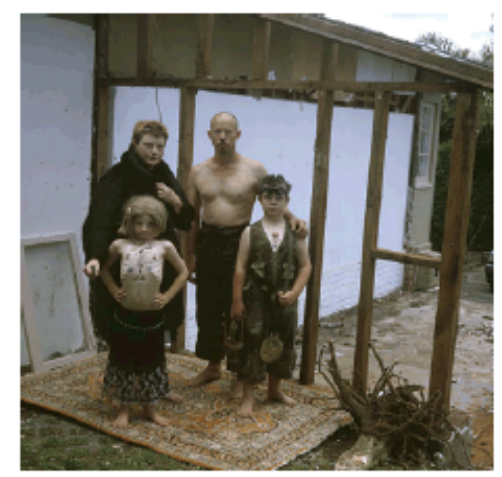

'Untitled \#1' Solar Familiar 2007

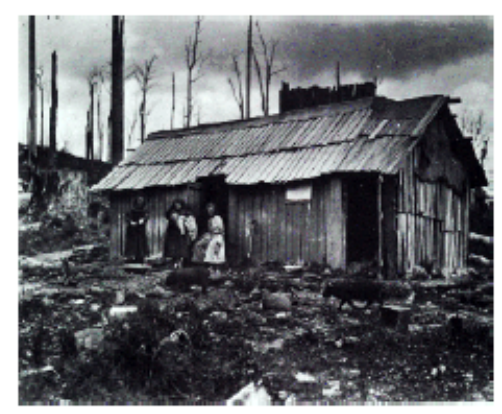

'Country Life' 1904. Photograph by J.N Taylor (Published with permission of the Alexander Turnbull Library, National Library, Wellington, New Zealand)

THE INTERNATIONAL JOURNAL OF THE ARTS IN SOCIETY, VOLUME 2, NUMBER 1, 2007

http://www.arts-journal.com, ISSN 1833-1866

(c) Common Ground, Marcus G. J. Williams, Susan E Jowsey, All Rights Reserved, Permissions: cg-support@commongroundpublishing.com 
Like all art; the project Solar Familiar raises more questions than it answers, has a multitude of cultural inflections and is fundamentally subjective.

This paper focuses on those aspects of Solar Familiar that deal with the correspondence between photographic documentation, lived experience and the human propensity for attraction to and rejection of 'otherness' with which this project engages.

Henri Lefebvre's conception of "lived space" imagined in a triadic relation with "perceived" and "conceived" space' is essential to the narrative of Solar Familiar. Lefebvre's assertion that the production of space is essentially relational, that we are all enmeshed in an intersecting body/space web, offers us a model of cultural/social connectedness that underscores the displacement portrayed in the photographs produced for this project.

The space we have staked out for ourselves is a mélange of the cultural physical and psychological... reality is a place where degrees of intimacy shrink and expand because they are governed correspondingly by the values of the individual and those enforced by the prevailing socio-cultural conditions. Whilst Solar Familiar simultaneously craves the habitat of cultural geography they appear unable or unwilling to navigate that matrix of negotiated space $\ldots$ and so have been assigned the role of outsider.
How is it then that Solar Familiar 'appears' to be estranged from a defining cultural paradigm... why have we sought to precipitate a cultural amnesia?

If space is relational then it is feasible to claim that a family in a movie could be perceived as corporeal, this breach in reality is where we begin our exposition of the notion of dispossession.

When one is drawn into another world via fiction and that fiction subsists in memory is not lived experience colonised? Such incursions supplant the real with the virtual, a dominion in which certainty does not adhere.

Clearly the three notions of space presented by Lefebvre are interdependent in creating an existential sense of being; of personal and cultural identity. It would therefore seem reasonable to assert, that in the event of an environment of exponentially accelerated privileging of conceptual space, as is the case with contemporary global culture, it is credible that the 'family in the movie' could become enduring if uncertain companions. Such slippery acquaintances are the product of a homogenising cultural trajectory in which the system of signs has become universalized and omnipresent to the extent that the sign system no longer refers to the world, it refers increasingly to itself and so becomes more significant to an understanding of the world than lived experience; hyperreality.

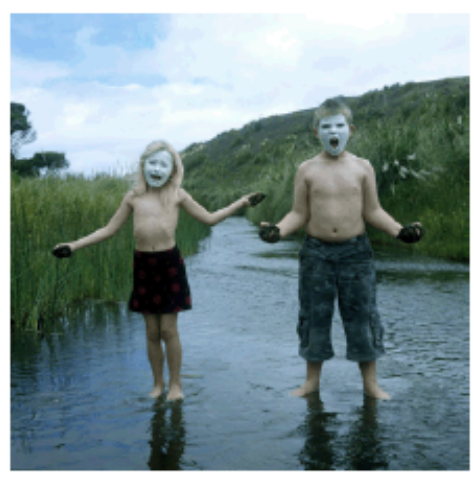

'Untitled \#2’ Solar Familiar 2006

As cultural mimics Solar Familiar raid from memory references to history yet their vision is mongrel parading as hyperaesthetic representations of lived experience. Their likeness is rendered idiosyncratic by a lack of substantive meaning - Solar Familiar's inability to cipher cultural innuendo obliges failure, caught between reflection and recognition - history awakens as folly.

The photograph in this project is a liminal landscape... like an ink-blot - its likeness stains the retina of sight, the outline of which evocates lost memory and lost identity. It is possible to conceive of Photographs as objects for the saviour of self, as photography presumes in some part that we may all lose either memory or identity or both. Decoding likeness, however, presupposes a body of signs from which mankind can draw similar inferences but Solar Familiar posits that no such body exists, even the trace of a greasy finger-print is particular.

Jacques Derrida, on being asked to expand on the origins of hyperreality replied '...but still it has always already begun to proclaim itself' (Derrida, 1978, p. 280).

Within only a few years of its invention, Feuerbach decried the position of photography '...our era...prefers the image to the real thing, the copy to the original, the representation to the reality, appearance to being' (Sontag, 1977, p. 153).

Whilst a documentary as a record occupies both a physical and a virtual space; it's visual relativity to lived experience means the viewer is able to suspend reality and be transported into another world; 
an unfamiliar world '...the copy (draws) on the character and power of the original, to the point whereby the representation may assume that character and that power' (Taussig, 1993, p. 18). Within this highly mediated facet of memory; where more is left outside the frame than is included, it is possible to know and define oneself as much by what one does not understand, as by what one does... here is territory uncharted - if the edge of the image is not the edge of the world what other fabrications lay beyond? Perhaps the image averts one from considering the possibility of more, it limits space to a moment...Solar Familiar capture themselves...they are both the subject and object of scrutiny...they limit themselves to an existence circumscribed by the veracity of negative space...they are photographic depictions become fetish...sealed in an embrace with the body to ward off impossibility.

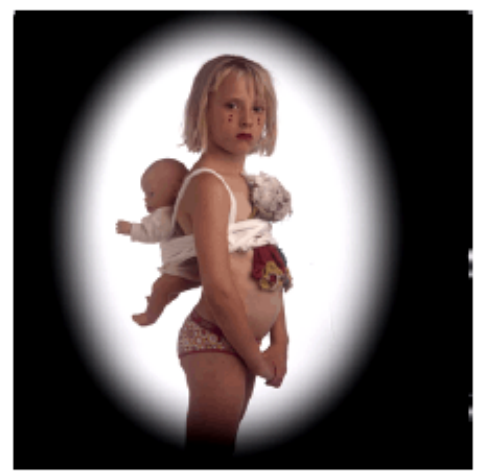

'Untitled \#3' Solar Familiar 2007

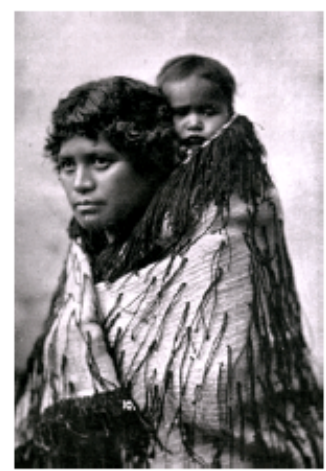

'Mother and her Child' c 1870. Photographer unknown. (Published with permission of the Alexander Turnbull Library, National Library, Wellington, New Zealand)

Truth is always negotiated territory most notably in a project that traverses a bipolar world - an interval with two extremes, that of the told and the untold story of a family - lost in space.

Let us consider then the visual relativity to lived experience of the documentary; in particular the photographic image. Semiotician Charles Pierce describes it as a form of signification that is indexical, the photograph being formed by a causal relationship with the physical world as opposed to social convention (symbol) or similarity (icon). Roland Barthes described it as the 'perfect analogon'.

The physical dimension of its signification has left an inescapable imprint of veracity in the popular conception of photography and has permeated its utility in every day life. Further, the ability of photography to capture a precise moment in time gives it a sense of absolute precision and an unquestionable link to lived experience. The photographic object makes solid the fluid precession of moments; it en- ables us to know the present in a manner not possible prior to its invention. As such Solar Familiar seeks to consume, as referents, images drawn from collective memory...fragments of lived experience cherished for their resistance to the virus of delusion... how is it then that Solar Familiar's interpretation of events is so unceasingly corrupted?

'The past' is shaped into a palpable object able to be reviewed, replayed and reproduced over and over, however, such production is attended by a stigmata - a mark of nostalgia. 'The photograph and its referent are forever, together frozen in a funereal and erotic embrace' (Barthes, 1981, p. 39).

The power of photography to solidify time is contingent on its status as object ...the moment frozen is, however, open to misinterpretation.

The instant we attempt to articulate or even construe a precise moment it has already passed into history rendering most other forms of signification including language, as byproducts of metaphor 
'...metaphor is not a mere extra trick of language, as it is so often slighted in the old schoolbooks on composition, it is the very constitutive ground of language. "... It is by metaphor that language grows. The common reply to the question 'what is it like?' is, when the reply is difficult or the experience unique, 'well it is like...? (Jaynes, 1976, p. 23). In this way language is incapable of representing the moment, since its analogous potential lays in the past.

It can be argued that photography does not work in this way; since a photograph operates within perceptual space; the parallels between the physiology of vision and the camera being well documented. '...the prosthetic eye became reconfigured as the movie camera. The early Soviet director Dziga Vertov so identified with this process that he claimed; "I am the cinema-eye. I am a mechanical eye. I, a machine, can show you the world as only I can see it”. Visuality was now photographic (Mirzoeff, 2001, p. 71).

Solar Familiar's use of the photographic is more akin to the metaphor of language...what is it like? Well it is not like... The photographs of Solar Familiar procreate a blemished library of images, a memoir of anxious fragments.

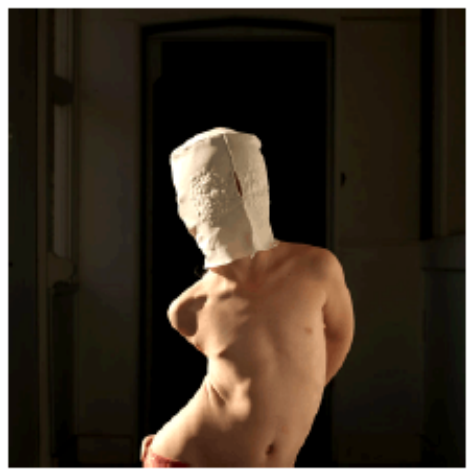

'Untitled \#4' Solar Familiar 2006

In 1982 the special effects company Lucasfilms declared that their work in computer imaging implied 'The end of photography as evidence for anything' (Mirzoeff, 2001, p. 88). Despite this claim and the concomitant rupture in the causal link between the world and photographic representation precipitated by digital imaging, the deeply embedded and integrated role of photography in the augmentation and indeed the construction of perceptual and conceptual space which one hundred and forty years of photographing (and filming), being photographed and viewing photographs has generated, are intact. More now than ever before, photography functions as the most ubiquitous tool by which we identify, validate and construct ourselves, to the point where lived experience is in some way simply not legitimate if not captured.

The act of legitimising is pivotal to this project... Solar Familiar's growing dossier of self-recordings is sanctioned by the power of photography to act as a witness. Their existence as a family lost is unassailable...here is the proof.

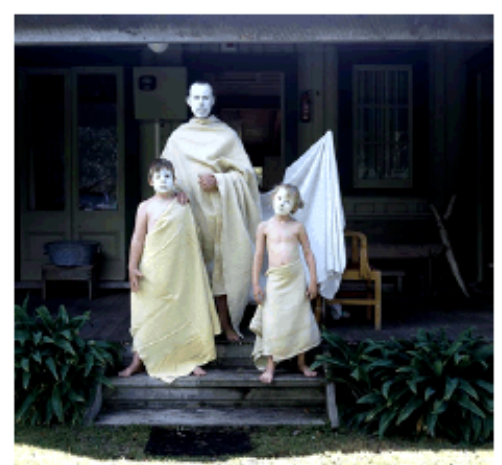

‘Untitled \#5’ Solar Familiar 2006 


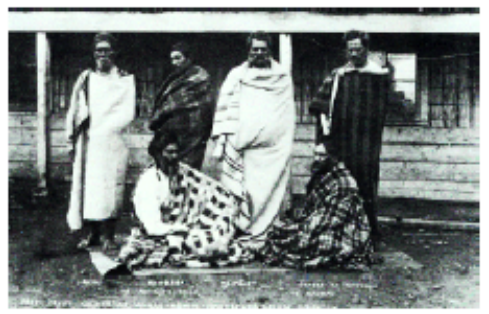

'Taonui Hikaka; Leading Ngati Maniapoto chiefs including Rewi Maniapoto’ c1881(?). Photograph by Alfred Burton. (Published with Permission of the Hocken Collections, Uare Taoka o Hakena, University of Otago, New Zealand)

The causal relationship between a photograph and its subject inevitably developed into the documentary traditions of modernity in both its still and motion picture form. The moment of arrival is usually marked by the photographs of the empty streets of turn of the century Paris by Eugene Atget. '...he photographed them like scenes of a crime. The scene of a crime too, is deserted; it is photographed for the purpose of establishing evidence' (Benjamin, 1968, p. 226).

The 'pencil of nature' became interchangeable with the thing itself and indispensable in the production of the proof of its being.

Solar Familiar are recidivists - they crave the vestigial assurance of the imprisoned moment - they are incessantly rearrange cultural clues - to know again, to see, yet the fastenings of memory have worked loose under the prying fingers of signification, every image affirms a perjury.

The photographic document in Solar Familiar depicts this struggle but if the moment is rendered impotent to what, if anything, does it establish evidence? Arguably, the constructed nature of the images problematises the truth to which they are intended to testify. On the other hand, the emphasis on the link with lived experience claimed by photography and passed into the popular unconscious, may itself be the dilemma?

Staged photography formed a vital part in early photographic production, ironically, often as a strategy for achieving higher degrees of realism due to the awkward nature of the technology. The delineation between photographs of staged and 'actual' events was not considered important in Victorian photography exhibitions. In Victorian albums “ "directorial" photographs comfortably coexist with more documentary ones' (Weiss, 2006, p. 82). The formality engendered by mid nineteenth century photography equipment provided the potential for quite a different image to that possible even by the 1880's when George Eastman first marketed roll film. The technical limitations imposed by equipment and processes contributed to the mannered and often collaborative nature of photographic portraiture where high degrees of subject input were quite normal.

Photography arrived at a time when various 'Victorian Parlor Games' were popular and became integrated into this $19^{\text {th }}$ century home theatre. 'By the time the invention of photography was announced in 1839 , the tableau vivant (a practice where family and friends dressed up to pose as protagonists in a famous scene from literature or painting) was an established form and it quickly became an obvious photographic subject' (Weiss, 2006, p. 86). In this manner one may suspect 'Solar Familiar' of being a postmodern parlor game. The use of photography in $19^{\text {th }}$ century anthropological fieldwork had a similarly less defined demarcation between the 'directorial' and the 'documentary'; something which changed as modernist photographic conventions unfolded in the $20^{\text {th }}$ century.

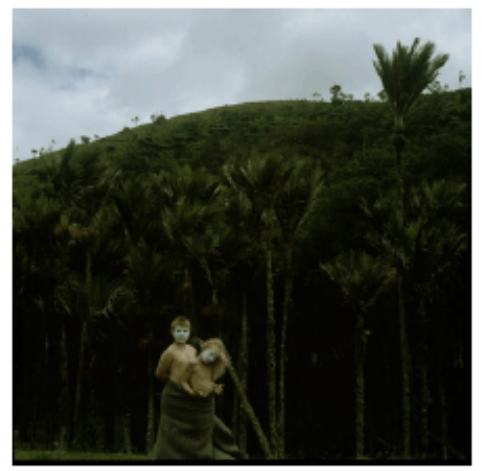

‘Untitled \#6’ Solar Familiar 2006 
The inter-subjectivity of Victorian photographic portraiture is paralleled in the commercially traded and popular photography of 'primitive' peoples (on which we have drawn) such portraits were frequently used in ethnographic and anthropological contexts.

Although produced later in the $19^{\text {th }}$ century, a collaborative tendency is demonstrated in Victoria Wyatt's study of photographs from the Winter and Pond Studio primarily of Tlingit and Haida Indians from South East Alaska. '...Almost always the native subjects knew the photographer was present, and usually the photograph could be taken only with the passive acquiescence or active cooperation of the subjects. The image that resulted reflects an interaction between the photographer and the subjects' (Wyatt, 1991, p. 23). The objective aspirations representative of a later paradigmatic shift in photographic theory and practice were not as pervasive at this time; despite an appreciation of the mediums intrinsically indexical quality alluded to in texts as early as Henry Fox Talbots 'The Pencil of Nature' published in six parts from 1844 to 1846.

Interestingly and perhaps ironically, anthropologists were determined to achieve the objectivity not regarded as important in Victorian photographic practice. In order not to influence the cultural activities being studied and to avoid the contaminating dangers of intimacy with the subjects, ethnographers and anthropologists went to great lengths to restage that to which their field notes pertained. '...In his Torres Straits fieldwork, Haddon, for example, made wide use of re-enactment and restaging as a means to document rituals and myth' (Poole, 2005, p. 166). The presumptuous and Eurocentric impulse to use photography to portray the world as seen from the perspective of the indigenous subjects, also motivated the staging of photographs. '...Haddon sought to use photography to portray what the natives 'saw' when they talked of mythology' (Poole, 2005, p. 166). The multi disciplinary social scientist W.H.R Rivers '...used mythical allegories drawn from Fraser's "The Golden Bough" in his curious photographs of the Todas...' in which '...Rivers sought to place natives in a mythical past' (Poole, 2005, p. 167).

The role of the staged image was further amplified by the development of Franz Boaz's notion of 'Salvage Anthropology'. The work of E. H Mann in the Andaman Islands is a good example of this, as commented on by Elizabeth Edwards, his meticulous recording of Andaman culture may have been felt by Mann as recompense for their sad fate; their physical and moral taming at the hands of the East India Trading Company. '... Mans photography...was a carefully posed and constructed image to complement his observations' (Edwards, 1992, p. 109).

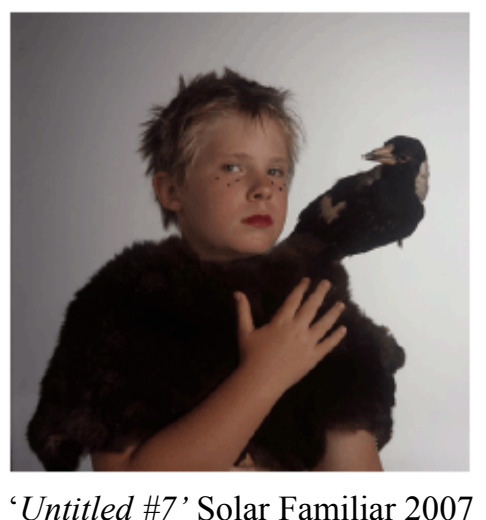

This compensatory impulse is interrelated with the neutrality and invisibility, which anthropologists strove for in their fieldwork, including photography and later film, in as much as it was a manifestation of a desire to preserve the primitive society in its natural form. The inevitable nostalgia associated with this 'Salvage paradigm' (Clifford, 1987, p. 120) was exemplified by the utilization of a variety of techniques borrowed from mainstream photographic portraiture such as soft focus and the vignette. These strategies, as argued by Deborah Poole, served to increase the appearance of vulnerability in the subject and in the case of the most famous exemplar of this aesthetic strategy, Edward Curtis, to '...transform the inevitability of extinction into the tragic romance of nostalgia' and '(the) framing of Native Americans as sad, inevitable and unresisting victims of a divinely manifest destiny (Poole, 2005, p. 167).

In this manner the specter of prepossession and contingency loomed over photographic documentation in early $20^{\text {th }}$ century anthropology leading ultimately to the decline in its use as an objective ethnographic document, however, such mortal failings offer a means by which the viewer can be lured into the web of association. Because Solar Familiar are chronicling themselves their myopic, alienated world is apt to cross proprietorial boundaries, the plasticity of interpretation binds the viewer to this cultural rupture; how does one escape the impulse, when presented with the tumult of another, to apply a set of cultural mores (not comprehend by the subjects)? The scrutiny of judgment implicates the viewer in 
the destabilization of the image and further aliena- tion/failure of the family.

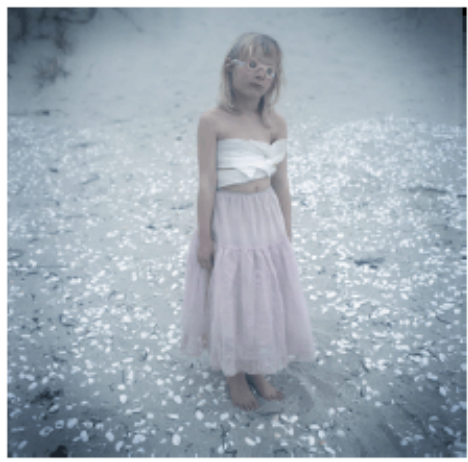

'Untitled \#8' Solar Familiar 2006

Manifestations of the inclination to preserve and to validate prejudicial notions of authenticity were the inclusion of props and costumery in studio photographs, which emphasized a closer relationship to nature than 'civilized society' or the exotic accoutrements of the heathen primitive. '... Winter and Pond probably included the robes because, as artists, they sought to engender rustic or even primitive ambiance... Similarly, Winter and Pond used a tree section as a prop in several images of Indians...' (Wyatt, 2001, p. 120).

Vital to Solar Familiar is the amplification of the drama with props and costumes; the theatre of family is mesmerized by the hegemony of objects in the conjuring of identity, nonetheless the objects that colonize Solar Familiar's vision only serve to cloak the confines of the blindness that besets them.

Solar Familiar is infested with 'things' that are tethered by personal history; correspondingly they too suffer the infection of loss. Objects also intersect Lefebvre's web and even though the presence of an object may be compromised, how we conceive or perceive it will seemingly alter reality. The collection of paraphernalia salvaged by Solar Familiar are essential to their story, they are the tracery scattered randomly by Hansel and Gretel to ensure their return home.

While the Romantic poets, painters (and later photographers) championed a philosophical search for transcendence in nature, for the 'natural man', in absolute antithesis and in what might be described as the nascent fields of social science; enthusiasts sought to employ the photographic medium in the emerging fields of criminology, physiognomy and phrenology.
The utilization of photography in each of these fields held in common the desire to develop standardized, empirical systems through which the study of the body and particularly the face would proffer insights into inner character. A case in point is the photographic composites of F. Galton who claimed the indexical veracity of the medium brought accuracy to the 'science' of physiognomy, which was not possible with textual description and measurement.

'The blur of their outlines, which is never great in truly generic composites, except in unimportant details, measures the tendency of individuals to deviate from the central type ' (Sekula, 1989, p. 368).

Like other practitioners of the time, Galton made claim for his technique to facilitate an infallible understanding of the social and racial 'types'; the Jew boy, the criminal etc. Mapping physical geography in a quest for identikits to human failure sanctions the fear that society is encumbered by a groundswell of the unfit. Diversity marks the human psyche, the surface of the skin tenders a multiplicity of inflections yet there remains an insistence on the photographic documentation of its aberrant members ... if the soul is captured by the lens then a wealth of archived spirits lay encrypted in the annals of history. Each one captured; pierced by a mug shot to the head.

Here too Solar Familiar strays - a palsy inhabits the body spellbound in the scope of the camera; petrified. The pelt of civility flayed the Family are haunted by an animalism the children snarl and scratch, the parents restless and anxious captured in states of undress they conform to notions of 'natural man'. 


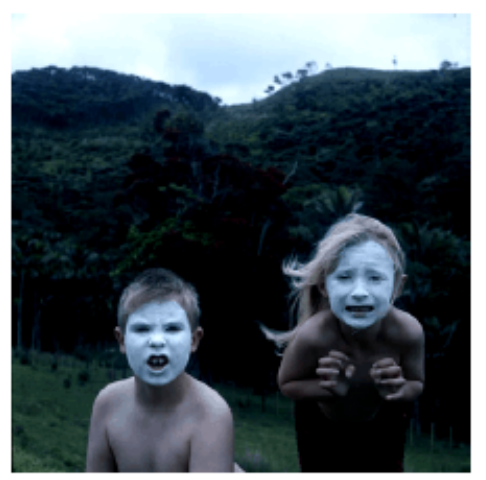

‘Untitled \#9’ Solar Familiar 2007

Here, the 'medical accuracy' of the camera is seen as invaluable in the construction of the '... enlightenment dream of a 'universal language' and for its '...capacity to reduce all possible sights to a single code of equivalence' (Sekula, 1989, p. 352). The role of the photograph as an exchangeable and universalizing archive is valued in its ethnographic application for its ability to '...permit the recovery of reliable comparative morphometric data (Pinney, 1992, p. 99).

Yet the bewilderment of this family is not contrived by a essentialist 'seeking to shore up' the historical landscape of those deemed 'outsiders', they have profiled themselves, their dissolution congealed in a chemical solution of their own making.

History is populated by those who have entered the web of empirical documentation unwittingly re- linquishing their likeness to classification - however, in this instance Solar Familiar have condemn themselves to idiocy - why?

The characterization of the inferior classes; the 'Criminal idler, indigent, vagrants, artists, criminals, children, savages, brutes, religious fanatics, idiots, madmen and women...' to quote the $17^{\text {th }}$ century philosopher John Locke is synchronous and synonymous with the emerging pre-eminence of 'truth' in photographic representation and the medical and anatomical imaging of the body. It is here that the role of photography in the production of a Foucaultian matrix of '...photography - vision - Western knowledge - power' (Pinney, 1992, p. 81). 'Thus photography came to establish and delimit the terrain of the other...' (Sekula, 1989, p. 345).

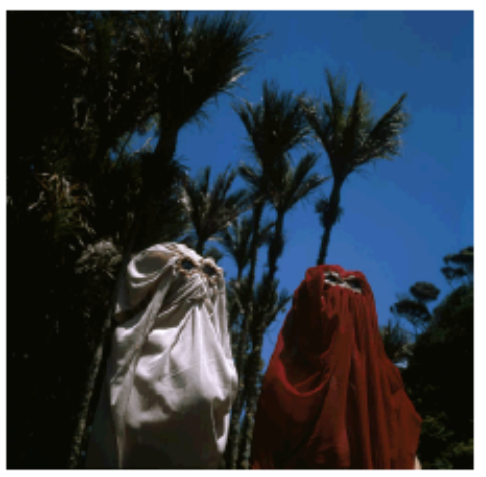

'Untitled \#10’ Solar Familiar 2007

In the scum of this power one always finds images of frailty; in order to re enact a sense of alienation perhaps we have amused ourselves within 'the matrix of lies' by role-playing, perhaps we are camouflaging the viciousness of truth? Increasingly we are interchangeable with the 'family in the film', the real family entwined in the production of a counterfeit photographic archive, which attempts to reconcile individual difference with a visual lexicon of "normality' - edifice is our dwelling place yet we are not unfamiliar; we are a contemporary family portrait. 


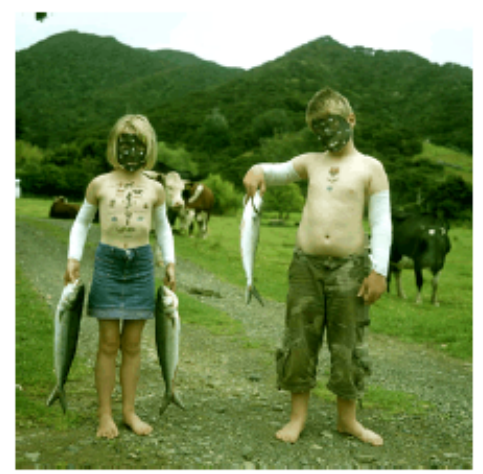

‘Untitled \#11' Solar Familiar 2007

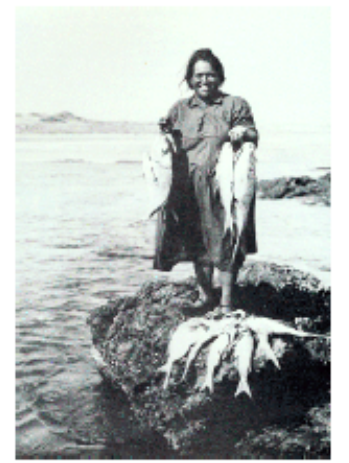

'Kia moana' date unknown. Photographer unknown. 'Mother and her Child' c 1870. Photographer unknown. Northwood Collection. (Published with Permission of the Far North Regional Museum, Kaitaia, New Zealand. Reference Number 250/8)

The role of the imaginary in the various histories of photography most notably ethnography, are testament to the maze of influences, which have come to bear on a form of signification which is synonymous with truth. As the 'place specific' geneologies of personal histories become increasingly fragmented; landscape inhabited by the family is a complex trap of truth and fiction, which as imaging technologies facilitate greater and greater realism, become more and more inextricable. If Solar Familiar can be lost and yet occupy a familiar landscape it begs the question 'Do we inhabit actual space or does the memory of the space, it's visual references inhabit us?' ...if we sift through our memories are images of this landscape not imbedded in us to be rediscovered and held up as a representation of ourselves when we are desperate to belong somewhere? It is as if one sense has failed and the other four cannot attune to the loss.

...so a devouring force comes at us from another direction, seducing us by playing on our yearning for the true real. Would that it would, would that it could, come clean, this true real. I so badly want that wink of recognition, that complicity with the nature of nature (Taussig, 1993, p. 17).

\section{References}

Barthes, R. (1981). Camera lucida; Reflections on photography. New York: Hill and Wang.

Benjamin, W. (1968). Illuminations. New York: Shocken.

Derrida, J. (1978). Writing and difference. Chicago: University of Chicago Press.

Edwards, E. (1992). The salvage anthropology of E.H Mann. In E. Edwards (Ed.), Anthropology and photography $1860-$ 1920. New Haven and London: Yale University Press.

Jaynes, J. (1976). The origin of consciousness in the break down of the bicameral mind. New York: First Mariner Books. Mirzoeff, N. (2001). An introduction to visual culture. New York: Routledge.

Poole, D. (2005). An excess of description: Ethnography, race, and visual technologies. Annual Review of Anthropology, 34(1), p159-179.

Sontag, S. (1977). On photography. New York: Farrar, Struas and Giroux.

Taussig, M. (1993). Mimesis and alterity - A particular history of the senses. New York: Routledge.

Weiss, M. (2006). Staged photography in the Victorian album. In L. Pauli (Ed.), Acting the part. London and New York: Merrill Publishers.

Wyatt, V. (1991). Interpreting the balance of power: A case study of photographer and subject in images of native Americans. Exposure 28(3). 


\section{About the Authors}

\section{Marcus G. J. Williams}

Marcus Williams is an artist, curator and Senior Lecturer at Unitec, New Zealand. Marcus has a cross-disciplinary art practice working in a wide range of media with a strong emphasis in photography. He makes artist's books, video's, photographs and web based projects, often combining these strategies into 'total installations'. He has an enduring interest in collaboration and has collaborated with a wide range of artists in NZ and in Europe. Marcus has exhibited throughout NZ and in Australia, UK, US, France, Italy, Austria, Estonia and Russia. His practice is primarily concerned with the uncertain dimension of human behaviour which lies somewhere between social and mediated experience. The process by which all that is biological or 'natural' (that wonderfully problematic word), is 'processed and codified into a highly complex system of signs. Cross disciplinary practice is central to his teaching; working in a generic Art and Design Program he facilitates projects between photography, sculpture, theatre, dance and screen arts students and continues to develop an exploratory, visually cognitive, developmental drawing course which focuses on the semiotic function of photographs, objects and texts to provoke ideas in students from a range of creative disciplines.

\section{Susan E Jowsey}

Susan Jowsey is a multimedia artist working with 3D objects, installation, moving image and photography. She lives in New Zealand but exhibits internationally. Her work is held in major collections throughout New Zealand. Susan's work has a strong visual aesthetic, drawing predominantly on the abject and found objects of domestic origin. Jowsey assembles a liminal Braille, marks made "for the saviour of self", she works with the presumption that we may all at some point lose either memory or identity or both. In this way her work is concerned with negotiating the lacework of memories contained within an object and often lost to the miasma of everyday existence. Jowsey only ever offers fragments to the viewer...tiny pieces skewed by personal longing, at best akin to markers each element struggling to form a readable whole, at worst incontrovertible proof of nothingness. Jowsey traces with her fingers a map of dislocation, in an exploration of identity, the fabric of habit, trace and breath and the clothes of the senses. 
THE INTERNATIONAL JOURNAL OF THE ARTS IN SOCIETY

\section{EDITORS}

Mary Kalantzis, University of Illinois, Urbana-Champaign, USA.

Bill Cope, University of Illinois, Urbana-Champaign, USA.

\section{EDITORIAL ADVISORY BOARD}

Robyn Archer, Performer/Director. Former Artistic Director, European Capital of Culture 2008, Liverpool, UK.

Tressa Berman, Executive Director, BorderZone Arts, Inc., San Francisco, USA; Visiting Research Faculty, University of Technology, Sydney (UTS), Australia.

Judy Chicago, Artist and Author, New Mexico, USA.

James Early, Director of Cultural Heritage Policy, Smithsonian Institution, Center for Folklife and Cultural Heritage, and Acting-Interim Director, Anacostia Museum Center for African American History, USA.

Mehdi Faridzadeh, President, International Society for Iranian Culture (ISIC), New York and Tehran, Iran.

Jennifer Herd, Artist, Curator, and Founding Faculty, Bachelor of Visual Arts in Contemporary Indigenous Arts, Queensland College of Art, Griffith University, Brisbane, Australia.

Fred Ho, Composer, Writer, Producer. New York, USA.

Andrew Jacubowicz, Faculty of Humanities, University of Technology, Sydney, Australia.

Gerald McMaster, Curator of Canadian Art, Toronto, Art Gallery of Ontario, Canada.

Mario Minichiello, Academic Director and Chair, Loughborough University School of Art and Design, UK.

Fred Myers, Professor and Chair, Department of Anthropology, New York University, USA.

Darcy Nicholas, Contemporary Maori Artist. General Manager, Porirua City Council, Pataka Museum of Arts and Cultures, Aotearoa/New Zealand.

Arthur Sabatini, Associate Professor of Performance Studies, Arizona State University, USA.

Cima Sedigh, President, Global Education and Health Alliance, Faculty of Education, Sacred Heart University in Fairfield, Connecticut, USA.

Peter Sellars, Opera Director, World Cultures Program, University of California, Los Angeles, USA. Judy Spokes, Director, Cultural Development Network, Australia.

Tonel (Antonio Eligio), Artist, Art Critic, University of British Columbia, Canada, and Havana, Cuba.

Marianne Wagner-Simon, Independent Curator and Producer, Berlin, Germany.

Please visit the Journal website at http://www.Arts-Journal.com for further information:

- ABOUT the Journal including Scope and Concerns, Editors, Advisory Board, Associate Editors and Journal Profile

- FOR AUTHORS including Publishing Policy, Submission Guidelines, Peer Review Process and Publishing Agreement

\section{SUBSCRIPTIONS}

The Journal offers individual and institutional subscriptions. For further information please visit http://ija.cgpublisher.com/subscriptions.html Inquiries can be directed to subscriptions@commongroundpublishing.com

INQUIRIES

Email: cg-support@,commongroundpublishing.com 